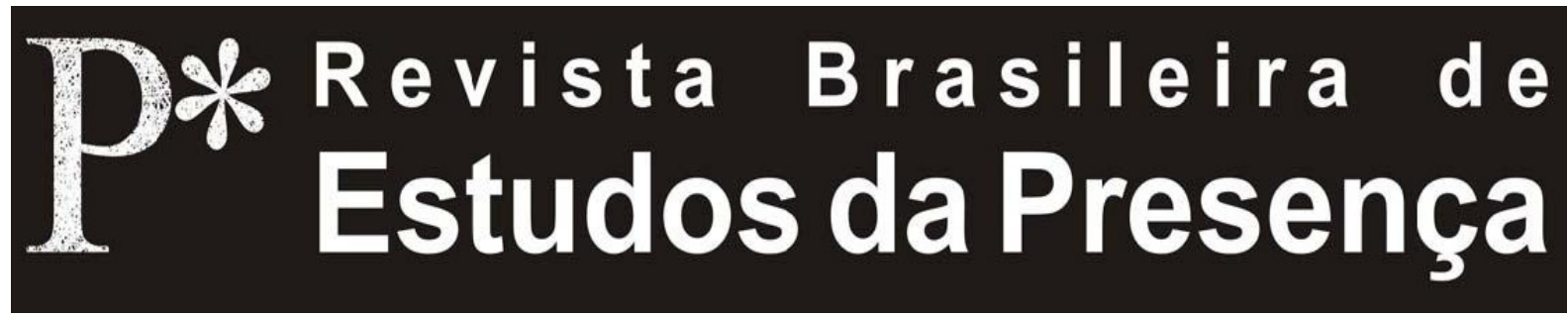

DOI - http://dx.doi.org/10.1590/2237-266037504

ISSN 2237-2660

\title{
Sobre Refuse The Hour, Kentridge e seus Espaços-Tempos de Criação
}

\author{
Fanny Le Borgne \\ Université Paris 3 Sorbonne-Nouvelle - Paris, França
}

RESUMO - Sobre Refuse The Hour, Kentridge e seus Espaços-Tempos de Criaçáo - Este texto discute, no cruzamento entre teatro, cinema e artes plásticas, a obra que o sul-africano William Kentridge desenvolveu desde o final dos anos 1980 de forma densa, polimórfica e multidisciplinar, circulando entre diversas formas de expressão o status de processo de criaçáo. Propõe-se pensar sobre a preparação de seus espetáculos, que é acompanhada por múltiplos vídeo-instalaçóes, gravuras, colagens e objetos. Este artigo mostra como esses vestígios de um trabalho de artista plástico, associados a um tempo de trabalho coletivo (os workshops), além dos ensaios, deslocam a análise genética dos seus espetáculos para outros espaços-tempos e outras modalidades de trabalho, que são diferentes do trabalho de cena.

Palavras-chave: Kentridge. Interdisciplinaridade. Processo. Ensaios. Atelier.

ABSTRACT - Around Refuse The Hour, Kentridge and his Space-Time of Creation This article deals with a creative process born in the intersection of stage, cinema and visual arts: the one of William Kentridge. In the polymorphic work of the South African artist, his movement between different forms of expression holds a key-role in his way of working. Taken between an installation and an exhibition, the progress around his show Refuse The Hour (2012) gives a relevant ground for the analysis of the stakes in a process of creation in movement between various artistic fields. From the studio to rehearsals, and through a rhythm of collective work, this text investigates the genetics of the show crossed by different space-times of creation.

Keywords: Kentridge. Interdisciplinarity. Process. Rehearsals. Workshop.

RÉSUMÉ - Autour de Refuse The Hour, Kentridge et ses Espaces-Temps de Creation - Cet article porte sur un processus de création né au croisement de la scène, du cinéma et des arts plastiques: celui de William Kentridge. Dans l'œuvre polymorphe de cet artiste sud-africain, la circulation entre diverses formes d'expression tient un rôle clef dans sa manière de travailler. Pris entre une installation et une exposition, le cheminement autour de son spectacle Refuse The Hour (2012) offre un terrain pertinent pour l'analyse des enjeux d'un processus de création en mouvement entre différents pôles artistiques. De l'atelier aux répétitions, en passant par un temps de travail collectif, ce texte explore une génétique du spectacle traversée par différents espaces-temps de création.

Mots-clés: Kentridge. Interdisciplinarité. Processus. Répétitions. Atelier. 
Da mesma forma que o seu uso emblemático do carvão, desenhando, apagando e redesenhando modificaçóes em um desenho para gerar, a cada captura de imagem, o movimento de uma sequência de animação, a finalizaçáo de um filme, assim como a de um espetáculo de William Kentridge, não apaga os gestos que acompanharam a sua preparação. Efetivamente, a produção de movimento pela supressão (inevitavelmente parcial) do carvão sobre uma mesma folha de papel favorece a persistência de traços, apesar da passagem da borracha e deixa uma espécie de cronofotografia dos gestos da máo do artista sul-africano. Por sua vez, seus três últimos espetáculos, $L a$ Flute enchantée ${ }^{1}, L e N^{2} z^{2}$ e Refuse The Hour ${ }^{3}$, são acompanhados de um corpus de realizaçóes anexas que lhes alimentaram e que inclui muitas formas nascidas durante a pesquisa como testemunhos do caminho que leva do processo à obra.

Autor de uma obra poliforme e interdisciplinar, no cruzamento da cena, do vídeo e das artes plásticas, William Kentridge aproveita a preparaçáo de cada espetáculo como uma oportunidade para circular entre seus modos de expressáo (desenho, gravuras, vídeo, filmes de animação, esculturas) e os imbricar. Por exemplo, sua habilidade na realização de imagens animadas ou fixas, ultrapassou sistematicamente as portas do seu atelier para integrar seus espetáculos sob a forma de projeçóes e de grafismos ou colagens reproduzidas em grandes telas pintadas na cenografia de La Flùte enchantée, Le Nez e Refuse The Hour. A elaboração de imagens gráficas ou cênicas, plásticas ou cinematográficas, aparece como a matéria transversal entre as etapas necessárias à preparação de seus espetáculos. Estudar essa matéria oferece um ponto de vista ideal sobre um processo de criação que se alimenta da circulação e do enriquecimento de ideias pela transgressão de gêneros, de campos e de práticas. Criados e desenvolvidos sobre essas bases multidisciplinares, os espetáculos de Kentridge carregam em si a sugestão dos tempos de criação fora do palco. São exatamente esses tempos, além dos ensaios, e esses vestígios de um processo de trabalho único que nós nos propomos a questionar.

Decididamente pluridisciplinares, seus espetáculos, assim como seus processos de gestação - para os quais Kentridge reuniu uma mesma equipe de colaboradores -, colocam questóes quanto às especificidades de suas elaboraçóes em um ambiente duplo: a distância do atelier e o imediatismo dos ensaios no palco. Nesse intermédio, um outro tipo de espaço-tempo preparatório, coletivo, se impôs, 
em direção ao qual convergem associaçôes de formas e ideias. Esses workshops, assim chamados pela equipe, e os ensaios, mostram as engrenagens de um trabalho cênico atravessado por múltiplos movimentos de criação.

Além das análises possíveis a partir da perspectiva de espectadora (ou de visitante, no caso das exposiçóes), o presente estudo se baseia em uma série de períodos de observação que eu tive a oportunidade de fazer durante a retomada das apresentaçóes de $L a$ Flûte enchantée ${ }^{4}$, Le Nez e Refuse The Hour ${ }^{6}$ na França, mas eu me apoiarei, particularmente, no caso deste último, Refuse The Hour. Com efeito, além das apresentaçóes assisti um workshop da equipe em Aix-en-Provence, em julho de 2011, e os ensaios para a estreia do espetáculo, em junho de 2012, no Teatro Frascati, em Amsterdã durante o Holland Festival. Esses períodos preciosos de observação tornam esse um contexto ideal para estudo.

\section{De um Diálogo entre a Arte e a Ciência, Duas Obras}

Em primeiro lugar, é preciso localizar o ambiente nada banal que acolheu e alimentou o surgimento dessa produçáo. Ao contrário dos dois espetáculos citados anteriormente, Refuse The Hour não é a encenaçáo de uma obra lírica (ou teatral) preexistente, nem mesmo o fruto de uma exploraçáo prevista para a cena. Por um lado, o mais novo espetáculo de Kentridge foi elaborado com base em um diálogo sobre o tema do tempo, entre o artista sul-africano e o físico americano Peter Galison (professor de História das Ciências em Harvard). Por outro lado, ele tem origem na encomenda de uma obra inédita para a $13^{a}$ edição da Documenta ${ }^{7}$. Primeiramente, este projeto de colaboração entre arte e ciência era destinado a realizar uma instalação - chamada The Refusal of Time ${ }^{8}$ - para esse grande evento de arte contemporânea, que acontece em Kassel (Alemanha) durante três meses a cada cinco anos.

As questôes do tempo e de sua percepçáo, das quais Galison (2005) é especialista, provocaram o interesse e o imaginário de Kentridge, que se confronta à manipulação do tempo na sua prática da animação. Trabalhar a imagem animada ou o filme é, na verdade, ter em suas mãos a possibilidade de fragmentar o movimento, de jogar com o desenvolvimento cronológico de uma narrativa, de inverter o tempo, acelerá-lo, retardá-lo ou repeti-lo em ciclos. Com o vídeo, a linearidade do fluxo temporal pode ser colocada em questão. Gali- 
son, por sua vez, se aplicou justamente a demonstrar a que ponto a percepçáo moderna do tempo tende a ser artificialmente objetivada e padronizada numa escala mundial (a sincronização dos relógios, o globo dividido em fusos horários e meridianos, a localização arbitrária do meridiano zero em Greenwich, etc.).

A partir desse campo comum de exploraçáo, ainda era preciso encontrar maneiras de se compreenderem um ao outro e de assegurar que suas respectivas abordagens do tempo encontrariam formas e uma sensibilidade em comum, para não correr o risco de que "[...] a arte se torne simplesmente um meio de ilustrar ideias científicas" (Galison, 2011, s. p.) ${ }^{9}$.

Peter Galison relata que foi a capacidade de associar o que pertence ao mundo das ideias a formas sensíveis e concretas que eles identificaram imediatamente como uma ferramenta de trabalho em comum. Eles “[...] descobriram logo um interesse comum por histórias, roteiros, nos quais elementos bastante abstratos são associados a fenômenos particularmente palpáveis" (Galison, 2011, s. p.) ${ }^{10}$. Assim, algumas histórias específicas atraíram suas atenções, como a surpreendente existência de um sistema de bombas pneumáticas sob as ruas de Paris para sincronizar os relógios municipais, ou ainda, a teoria de Felix Eberty, que imagina a galáxia como uma gigantesca sala de arquivos universal. Aliás, essa inclinação comum para expressar uma teoria de uma forma palpável (através de anedotas, metáforas, histórias) foi consolidada por um interesse compartilhado em um período histórico: o fim do século XIX. Carregada pela atmosfera característica da revolução industrial, a iconografia dessa época e das suas invenções mecânicas fascina a ambos.

\section{The Refusal of Time, do Diálogo às Duas Obras: um processo visível}

Produzido por uma agência artística francesa (TomorrowLand, dirigida por Caroline Naphegyi) e composto pela mesma equipe de colaboradores reunida para La Flûte enchantée e Le Nez ${ }^{11}$, o projeto passou por formas e caminhos variados, às vezes provisórios ou preliminares como as etapas de criação, às vezes conservados em paralelo, antes de resultar em The Refusal of Time, a instalação encomendada, assim como no espetáculo Refuse The Hour, surgido como uma segunda via de criação necessária ao longo dos dois anos de desenvolvimento. 
Para muitos artistas, a criação definitiva (se realmente existe um definitivo nas artes do espetáculo) está no final de um conjunto de possibilidades destinadas a serem esquecidas e apagadas para guardar somente a forma final da produção. No caso de Kentridge, no entanto, as etapas passadas, abandonadas ou preliminares, não são escondidas. Muitos dos objetos e documentos que poderiam ser apenas rascunhos e material visual necessários para Refuse The Hour ou para The Refusal of Time tendem, através de mostras públicas (exposiçóes, apresentaçôes e/ou publicaçóes), a ser considerados como verdadeiros objetos ou eventos artísticos. Seguir os vestígios desses materiais permite a observaçáo de quase todo o caminho pelo qual a equipe passou.

La Négation du Temps - Prologue ${ }^{12}$, exposição exibida no $L a-$ boratoire, em Paris, e Dancing with Dada, uma primeira versáo de Refuse The Hour, apresentada em setembro de 2011 no Market Theatre de Johanesburgo, são parte dessas etapas do processo mostradas e divididas com o público. Colocados face aos espectadores e visitantes, esses eventos - retomados nas propostas finais sem terem sido reapresentados em suas formas originais - diluem as fronteiras entre a preparação e a obra.

Esses eventos mostram a tomada de consciência da fascinação que o acesso ao processo de criação pode exercer no público. E eles mostram também o interesse do artista e de sua equipe em longos processos que pedem novas maneiras de criar juntos. A exposição do Laboratoire exibia os primeiros filmes feitos sobre o tema, máquinas com engrenagens à mostra (inspiradas pelo maquinário do século XIX) e esboços do trabalho dos futuros atores do espetáculo, nos filmes. Ela expunha a maneira como a sensibilidade do artista encontrou eco no cientista e como cada um dos colaboradores recorrentes de Kentridge pôde se aproximar desse trabalho antes mesmo de se pensar em fazer um espetáculo ${ }^{13}$. As intençóes e os objetivos que ela representou em um dado momento revelam, também, comparados aos resultados finais do projeto, as transformaçóes e questionamentos que surgiram posteriormente para a equipe.

Particularmente representativa dessas modificaçóes trazidas pela passagem do tempo durante um projeto, a comparação de Dancing with Dada, espécie de work in progress público, com Refuse The Hour, sua evolução direta, revela mais do que a simples escolha de uma mudança de título. Apresentadas com nove meses de intervalo, Dancing 
with Dada fixava uma estrutura geral bem próxima à do espetáculo futuro: já estavam presentes as grandes telas pintadas - suportes para as projeçóes - que cobriam o fundo do palco, permitindo apenas a passagem dos atores; o uso de um texto escrito por Kentridge (baseado em conversas com Galison, em suas experiências e em episódios pessoais) como livreto; a divisão do espetáculo em quadros com sequências temáticas e a reutilização massiva das imagens em vídeo e das ideias de máquinas mostradas anteriormente no Laboratoire. $\mathrm{Na}$ estreia de Refuse The Hour, dia 18 de junho de 2012, o público redescobriu as telas pintadas em uma nova organização cenográfica (que lhes dá outras possibilidades além de telas de projeção). Os espectadores puderam observar também os resultados de um trabalho de aperfeiçoamento do texto, de encadeamento das cenas, de precisão do jogo e dos deslocamentos dos atores. Um conjunto de modificaçóes que valoriza as possibilidades trazidas pela cena aos modos de instalação. Desde os primeiros fragmentos de pesquisas apresentados na exposição do Laboratoire até Dancing with Dada e, em seguida, Refuse The Hour e/ou The Refusal of Time, esses vestígios de um processo (aos quais novos desenhos, filmes e máquinas continuaram se agregando) permitem uma compreensão do trabalho de Kentridge e de sua equipe através das etapas do seu desenvolvimento.

Com a publicação de The Refusal of Time (2012), uma obra que atravessa o conjunto das formas criadas a partir da instalação e do espetáculo, dar ao público um acesso aos percursos da produção de Refuse The Hour surge como uma problemática possível em si mesma (e não mais como apenas uma consequência do trabalho). Ao reunir anotaçóes de William Kentridge e de seus colaboradores, fotografias de ensaios e de workshops, textos ouvidos na instalação e no espetáculo, mas também desenhos inéditos feitos especialmente para esta publicação, o livro The Refusal of Time varia entre o status de vestígio, explicação e objeto de arte. Ele mostra a complexidade da apreensão de elementos tirados de um processo de criação em constante movimento.

Sujeito a questionamentos que Kentridge não deixou de aproveitar na sua maneira de trabalhar, os movimentos do pensamento e das ideias no processo de criação tornam-se um fio condutor que Refuse The Hour integra à trama do tempo, explorada pelo conjunto desse projeto de múltiplos resultados. 


\section{Na Mente do Artista: o atelier}

Em uma forma única que cruza texto, canto, música ao vivo, dança, vídeo, telas pintadas e manipulação de objetos, Refuse The Hour pode ser considerado, em primeiro lugar, como o fruto de uma retomada cênica das histórias, das ideias exploradas e das imagens feitas inicialmente para a instalação. O espetáculo propóe uma identificação com as suas questôes sobre a passagem do tempo. Mas não se resume somente a isso.

Em um dispositivo cenográfico que faz uma mise-en-abyme do espaço de cena (formado por telas pintadas na vertical e um friso alto representando uma cortina de teatro) o palco é dividido por uma plataforma que constitui um segundo nível com a metade da profundidade (como a marcaçáo entre o palco e o proscênio), William Kentridge está em cena, interpretando a ele mesmo. Ele fala para o público ou para si mesmo o texto que ele escreveu baseado em suas conversas com Galison, em histórias e em reflexóes pessoais, enquanto o resto dos elementos de cena se articulam dentro dessa estrutura dramatúrgica (canto, dança, música ao vivo, manipulação das máquinas e, é claro, projeções de vídeo). Sem exageros, sem personagem, vestido da maneira como é conhecido (camisa branca de manga comprida e calça preta), ele carrega um caderninho cheio de anotaçôes e desenhos, exatamente como o que ele usou durante todo o processo de preparação do projeto e cujas páginas aparecem sendo folheadas nas projeçóes de vídeo. Ele interpreta seu próprio papel de artista. Suas intervençóes pontuam um espetáculo sem diálogos e sem fio narrativo e são breves como um fluxo de pensamentos pessoais, fragmentados em diferentes temas. Ao aumentar o horizonte da pesquisa feita para a instalação, o espetáculo valoriza a relação íntima e artística de Kentridge com o espaço-tempo da criação: um convite para mergulhar na sua mente e no seu atelier, lugar de origem das imagens e da associação de ideias e formas no seu trabalho.

Espaço de concepçáo do conjunto das criaçôes, cênicas ou plásticas, o atelier do artista é o lugar privilegiado da efervescência instintiva e produtiva da consciência. Mais do que isso, para Kentridge, o atelier é o órgão responsável pela junção das ideias, formas e imagens que alimentam profundamente a sua prática.

No atelier, é muito mais fácil. Existem diferentes fragmentos [...], por todas as paredes do atelier. Você pode ver tudo com apenas uma olhada, você pode colocar, justapor esses fragmentos em diferentes configuraçóes (2012, s. p. $)^{14}$. 
A possibilidade de visualizar, com apenas um olhar, todo o material criado em um projeto faz de uma caminhada do artista em seu atelier um verdadeiro passeio no seu cérebro. Ao considerar o atelier como um prolongamento concreto da sua mente, o fato de poder visualizá-lo torna-se uma ferramenta que estimula e alimenta a reflexão. Mais ainda, ao tornar visível e acessível o conjunto do que já foi desenvolvido, assim como de pesquisas mais antigas, o atelier torna-se um agente do processo de criação em progresso. Os impulsos de Kentridge durante a criação aparecem frequentemente, segundo ele, "de uma negociaçáo entre si-mesmo e o que vem de fora" (2012, s. p. ${ }^{15}$. O espaço-tempo do atelier mostra a aplicação concreta dessa dinâmica, na alternância entre duas posiçóes: a experimentaçáo de novas formas e o distanciamento regular (físico, se afastando para ver melhor, e intelectual) sobre o trabalho em processo.

No espaço entre fazer e olhar, o ambiente do estúdio e o momento presente são, muitas vezes, as fontes de decisóes e do surgimento de ideias possíveis. Sem premeditação, um objeto percebido por perto, uma palavra lida ou ouvida, um olhar em torno das criaçóes presas nas paredes inspiram, de maneira consciente ou não, escolhas que, de outra forma, talvez nunca tivessem sido feitas. É o que aconteceu no caso da criaçáo dos figurinos da bailarina Dada Masilo e da cantora Ann Masina para Refuse The Hour. Com efeito, quem assistiu Le Nez e La Flûte Enchantée pôde reconhecer que a saia usada por Dada Masilo tinha as mesmas colagens que aparecem no cenário da encenação da ópera de Shostakovich [ $\mathrm{Le} \mathrm{Nez}$ ]. A saia de Ann Masina faz um paralelo com os figurinos dos personagens das Três Senhoras [em La Flûte Enchantée]. Isso se deve ao fato que, durante as experimentaçóes dos workshops, que foram coletivos, a figurinista fez seus primeiros testes recuperando pedaços dos tecidos utilizados nas telas de fundo de Le Nez e nas provas de figurino de La Flûte Enchantée. Essa recuperaçáo sem sentido aparente acabou sendo conservada no espetáculo e nos filmes da instalação. Esse exemplo reposiciona o atelier em seu papel de espaço de convergência das propostas dos colaboradores que cercam Kentridge nas suas produçôes.

Espaço íntimo de criação, no qual Kentridge volta à calma e ao ritmo da ação sem intermediários, após a efervescência e a agitação das óperas e dos teatros, o atelier pode eventualmente ser o lugar de algumas sessôes de trabalho coletivo. 


\section{Workshops, Matrizes Experimentais}

Se associar a outras pessoas para criar uma obra não assusta William Kentridge e parece, inclusive, ter guiado e alimentado sua maneira de trabalhar, tendo em vista que ele chegou a incluir o coletivo (próprio do teatro) no seu atelier e nas suas produçóes de artes plásticas. O diálogo com Peter Galison, que baseou o trabalho de The Refusal of Time e Refuse The Hour, é uma prova disso. No entanto, gostaríamos de abordar agora o lugar e o funcionamento do trabalho de Kentridge com sua equipe de colaboradores frequentes, alguns pelo menos desde a produçáo de La Flûte Enchantée, outros há mais tempo ainda. Catherine Meyburgh, diretora e editora de filmes e vídeos, e Philip Miller, compositor, já trabalhavam em algumas criaçóes de Kentridge desde o final dos anos 1990. Passaram a integrar esse grupo a partir de 2003, durante a preparação da ópera de Mozart (que estreou em 2005 no Théâtre de la Monnaie, em Bruxelas), Sabine Theunissen, arquiteta e cenógrafa, Luc Dewit, diretor de atores e ex-colega de Kentridge na escola de teatro Jacques Lecoq, em Paris, e Greta Goiris, figurinista.

Não foi apenas o sucesso dessa primeira produção em conjunto, La Flùte Enchantée, que estimulou Kentridge a repetir a experiência durante a criação de Le Nez e de Refuse The Hour. "Uma das vantagens de trabalhar com a mesma equipe, além das competências individuais e do fato de que já sabemos como trabalhar juntos, foi a possibilidade de conhecer o temperamento de cada um" (Kentridge, 2011(a), s. p.), ressaltou o artista falando sobre a reuniáo da mesma equipe para a criação de $L e N e z$. Além das competências técnicas desejadas ou da necessidade de delegar para poder produzir esse tipo de projeto, sobretudo em uma ópera, existe um interesse pelo trabalho específico dessas pessoas e por seus universos sensíveis, que tornou essa colaboração cada vez mais sólida com o tempo. Refuse The Hour, que integra também Peter Galison e Dada Masilo ao grupo, confirma e desenvolve essa atração pelo trabalho coletivo. Com efeito, livre da forma e das convençóes interdisciplinares impostas pela ópera, o fato de trabalhar com um grupo de indivíduos vindos de diferentes áreas de conhecimento é uma escolha assumida de criar uma obra coletiva.

Náo se trata apenas do fato que cada um tem uma atividade específica, [...] mas é o projeto como um todo que se desenvolve a partir desta equipe de cinco ou oito pessoas que observam, sugerem, tentam ver como as máquinas podem 
ser acionadas, qual tipo de ação combina melhor com cada máquina, e qual figurino é possível com esse tipo de ação (Kentridge, 2012(c), s. p.).

Ao pontuar as diferentes etapas de execução e organização da temática do tempo, os workshops - assim denominados pela própria equipe - reúnem esses diferentes colaboradores da concepção artística de Refuse The Hour (e de The Refusal of Time), que estão envolvidos no projeto mesmo quando geograficamente separados (Bélgica, Estados Unidos, África do Sul). Caroline Naphegyi, responsável pela produção global do projeto $A$ Negação do Tempo (exposiçôes, instalação, espetáculo, publicação), define os períodos anteriores aos ensaios segundo seu ponto de vista do processo: "[...] um workshop é a reunião, o trabalho experimental de improvisação a partir do qual [Kentridge] constrói a obra" (Naphegyi, 2011, s. p.).

Durante alguns dias consecutivos, várias vezes ao longo dos dois anos de preparação de The Refusal of Time e de Refuse The Hour, os workshops reúnem Kentridge com todos os seus colaboradores para confrontar, reunir, procurar, provocar imagens e ideias. A partir dessa intenção de fazer uma abordagem aberta e experimental, se encontram as matrizes de um processo coletivo. Trata-se de elaborar dispositivos e vocabulários, descobertos e testados coletivamente. Eles formam, pouco a pouco, o material a ser organizado na nova produção: a "caixa de ferramentas do projeto" (Theunissen, 2011, s. p.), como eu pude ouvir Sabine Theunissen qualificar os workshops. Esboços e projeçôes aparecem rapidamente como base para o trabalho da equipe e, progressivamente, se elaboram os figurinos e o jogo dos atores a partir das indicaçôes de Kentridge. Verdadeiros cruzamentos de disciplinas e de artistas, os workshops de Refuse The Hour desenvolvem ainda mais a experiência do diálogo entre mídias e sensibilidades como processo de criação coletiva. Desde os primeiros workshops, antes da exposição no Laboratoire e após o início dos diálogos com Peter Galison (um fato inédito nesse projeto), atores e cantores foram incluídos e músicos sul-africanos, de diferentes horizontes musicais, foram convidados. Todo o necessário estava reunido em torno da equipe artística para ver o que poderia nascer da junçáo ou da confrontação de cada um. Segundo Caroline Naphegyi:

O trabalho se constrói através de diferentes etapas e camadas sucessivas de improvisaçóes, nas quais, por exemplo, ele faz passarem os atores utilizando as máquinas com uma

Fanny Le Borgne - Sobre Refuse The Hour, Kentridge e seus Espaços-Tempos de Criação 
projeção no fundo da cena, mas ele re-filma esse desfile e, em seguida, ele acrescenta sua intervençáo pessoal, como ator, como artista (Naphegyi, 2012, s. p.).

Em julho de 2011, em uma cidade próxima de Aix-en-Provence, eu tive a oportunidade de assistir um desses workshops para o desenvolvimento do projeto The Refusal of Time. Juntos com as reapresentaçóes de Le Nez, Kentridge, Theunissen, DeWit e Meyburgh receberam Miller e Galison durante três dias de trabalho coletivo. $\mathrm{Na}$ mesma época, a exposição La Négation du temps - prologue no Laboratoire tinha terminado, após mostrar ao público um material rico mas ainda muito bruto, construído durante os workshops anteriores. Filmes, máquinas, desenhos e objetos foram expostos como uma pesquisa de vocabulário a ser reapropriada na obra que estava sendo preparada para a Documenta. Justamente, foi durante o workshop de Aix-en-Provence que surgiu a necessidade de criar um espetáculo. A ideia inicial era de criar uma performance musical ao vivo, dentro de uma instalação formada por projeções e máquinas. Mas, a partir de uma iniciativa de Philip Miller, o texto explicativo escrito por Kentridge foi transformado em livreto para a música. Nesse contexto, era mais pertinente que Kentridge fizesse a leitura de seu próprio texto durante a performance. Ao mesmo tempo em que a necessidade da presença quotidiana do artista na instalação performática durante os três meses da Documenta parecia ser um problema, a energia dos músicos sul-africanos que tinham participado dos primeiros workshops tornava frustrante a perspectiva de substituí-los por músicos alemães durante o evento. Por essa razáo, o caráter performativo da instalação foi completamente retirado - incluindo a música ao vivo - e utilizado em uma nova forma, paralela: o espetáculo Refuse The Hour. "Nós decidimos fazer os dois caminhos diferentes, que utilizam as mesmas imagens, os mesmos sons, mas de maneiras diferentes" resume Kentridge (2012d, s. p.).

Nos workshops e durante o processo de criação do espetáculo, a utilização dos elementos desenvolvidos guardava seu caráter incerto e maleável. Assim, indicaçôes que serviam para a direção dos atores foram transformadas em material para o vídeo e os vídeos foram integrados tanto à instalaçáo quanto ao espetáculo. Deixar um espaço livre para a dúvida e a flexibilidade em relação ao material criado ou em fase de produção é um aspecto importante na maneira de trabalhar de Kentridge. Até o momento de tomar decisóes definitivas, o artista considera a dúvida (em oposição à certeza) como um espaço 
de pesquisa saudável. Para isso, trabalhar a partir de improvisaçóes e experimentaçóes garante a ele e a seus colaboradores uma liberdade de expressão e de sugestão durante o processo. No entanto, cada uma das decisóes finais é responsabilidade de Kentridge que, segundo Sabine Theunissen, é o "guardiáo" do trabalho. "Eu preciso trabalhar com colaboradores que possam compreender circunstâncias [de trabalho] nas quais existe uma conversa e uma colaboração integrais, mas nas quais eu não seja obrigado a aceitar ideias que náo me convencem completamente" (Kentridge, 2011(a), s. p.). Trata-se de um papel de diretor artístico que ele não abandonou, mesmo estando presente no palco como ator (submetendo-se, nesse caso, às observaçóes de sua equipe) durante os ensaios de Refuse The Hour.

\section{Dirigir Atuando - os ensaios de Refuse The Hour}

Em junho de 2012, no Théâtre du Frascati de Amsterdá, apesar dos workshops, dos ensaios que ocorreram nessa época e de Dancing With Dada, os ensaios do espetáculo não deixaram de ser um espaço-tempo de diálogo, sugestôes e mudanças de direção do trabalho coletivo. Várias das escolhas e das ideias sofreram reajustes e readaptaçóes tendo em vista uma comunháo cada vez mais precisa de todos os elementos que se instalariam durante a performance.

Como um olhar exterior, testemunha bem recebida por toda a equipe, eu assisti durante cinco dias à organização do espetáculo no palco. Da evolução dos deslocamentos e das posiçóes dos atores - incluindo Kentridge - e dos objetos no palco, até às atuaçóes possíveis em função do uso do espaço da instalação (três espaços diferentes que foram ocupados), tudo estava aberto a mudanças até o momento do ensaio geral. Como mão de obra suplementar para a equipe, eu ajudei a reunir os últimos acessórios, a repintar uma faixa horizontal abaixo das telas do cenário (cuja altura não correspondia aos limites do vídeo projetado na tela) e a escurecer um praticável, de última hora: a iluminação deixava o objeto muito claro, com um aspecto asséptico, novo, limpo demais na opiniáo da equipe, especialmente da cenógrafa, que queria evitar comparaçóes com um chão exposto em uma loja de decoraçáo.

Mesmo tendo passado a responsabilidade das suas imagens para Catherine Meyburgh, Kentridge continuou dividido entre seu status de diretor artístico - observando o espetáculo como um todo - e o de ator, presente em cena. Ao ter que confiar no olhar dos seus 
colaboradores para encontrar seu lugar, seu papel e seus gestos (razão da importância da relação de confiança estabelecida entre eles desde La Flûte Enchantée), ele continuou na sua posição de guardião, indo e vindo entre o palco e a plateia. Graças à cumplicidade de Luc Dewit, que o substituía no palco, Kentridge pôde se dar conta das escolhas sugeridas e dos seus resultados, antes de tomar uma decisão definitiva. Encontrar o equilíbrio entre as disciplinas reunidas, entre a imagem e o real, entre seu lugar de ator e seu olhar de diretor, foram as questôes desses ensaios nos quais transparece a influência do trabalho do atelier: a capacidade que a equipe desenvolveu de se distanciar regularmente das escolhas e colocá-las em questáo mesmo às vésperas da estreia.

\section{Conclusáo}

No trabalho de William Kentridge, o aspecto polimórfico, multimodal e multidisciplinar das etapas que constituíram o processo criativo de Refuse The Hour é o resultado lógico de um ambiente específico e central de criação: o atelier do artista. Nesse espaço, plataforma onde cada nova forma imaginada do projeto se comunica, o artista utiliza todas as potencialidades que suas ferramentas e suas ideias possibilitam. Ele varia também as formas de trabalhar, passando do trabalho solitário às experimentaçóes sem ideias preconcebidas, do estímulo das propostas coletivas da equipe às tentativas aplicadas aos ensaios, com os atores.

Ao reunir teatro, dança, vídeo, música, artes plásticas e ciência, os vestígios (preparatórios) e os objetos que pontuam o processo de criação refletem a polivalência de seu universo, mas também sua maneira de pensar. "Aceitar o deslocamento do pensamento e das imagens" (Kentridge, 2011(b), p. 25), essa afirmação de Kentridge, em uma entrevista com Denise Wendel-Poray, não seria uma porta de entrada para abordar as mudanças e circulaçóes de imagens no seu processo e na sua obra? Uma ode ao laisser-faire do surgimento - provocado ou inesperado - das ideias: essa afirmaçáo valoriza o cruzamento de fronteiras e a dinâmica do pensamento em movimento. Considerar esse deslocamento como um agente de criaçáo determina, em grande parte, a maneira como Kentridge concebe seu processo de trabalho.

Concretamente, esse ponto de vista sobre a mecânica do pensamento, aplicado ao ato de criação, se traduz, antes de tudo, por 
uma dessacralização, uma liberação do gesto e do estatuto do objeto final. Fazer, sem se preocupar em saber a finalidade ou a ideia que possa aparecer, é uma tendência enfatizada também por Bronwyn Law-Viljoen em seu livro sobre a concepção de La Flûte Enchantée:

No lugar de encontrar seu caminho conceitualizando um projeto como La Flûte enchantée, Kentridge trabalhou desenhando, fazendo gravuras, rasgando pedaços de papel, construindo figuras mecânicas, construindo teatros em miniatura, mexendo em objetos comuns sobre a mesa, instalando uma câmera e testando projeçôes em diferentes telas de fundo (Law-Viljoen, 2007, p. 19) ${ }^{16}$.

Encontrar sua verdade na ação reflete uma desconfiança profunda da lógica manipulável dos discursos e do desenvolvimento retórico e argumentado do pensamento. Ao fazer um contraponto com a superioridade, muitas vezes inapropriada, da retórica, Kentridge rejeita o jogo da construção da linguagem e da afirmação de certezas, preferindo o provisório, o momento presente do atelier e as tentativas.

Agentes e observadores privilegiados da produtividade formal que resulta dessa dinâmica, o espaço do atelier e o tempo de trabalho coletivo são matrizes - complementares - do duplo desenvolvimento de The Refusal of Time e de Refuse The Hour. Os ensaios, frequentemente centrais no processo de criação de um espetáculo, se encontram em um espaço intermediário entre o atelier e o palco. Eles se situam entre o material atualizado no estúdio e o surgimento de novas decisóes, impostas pelo trabalho de palco e seu caráter imediato. No contexto de criação desenvolvido pelas relaçóes formais entre a instalação, o espetáculo e as etapas de preparação (exposição, Dancing With Dada, workshops), as transformaçôes, as reutilizaçôes, as repetiçóes e os abandonos de ideias e imagens criam a lógica de um processo náo linear que Kentridge define da seguinte forma:

[...] o pensamento pode seguir um caminho específico, mas existem todos os caminhos que não foram seguidos, e todos os outros que continuam sendo pensados no momento, ou aqueles que náo foram pensados ainda [...]. Por isso eu não falo de um 'fluxo de consciência', solitário e difuso, mas de uma 'autoestrada de consciência' na qual se tem um corredor com muitas pistas diferentes e coisas se deslocando em cada pista, ultrapassando, parando, saindo da rodovia (Kentridge, 2007, p. 23) ${ }^{17}$. 


\section{Notas}

${ }^{1}$ A Flauta Mágica, de Wolfgang Amadeus Mozart, direção e vídeos de William Kentridge, estreia no Théâtre de la Monnaie, Bruxelas, 2005.

${ }^{2}$ O Nariz, de Dmitri Shostakovich, direção e vídeos de William Kentridge, estreia no Metropolitan Opera, Nova York, março de 2010.

${ }^{3}$ Refuse The Hour, direçáo, texto e vídeo de William Kentridge, estreia no Frascati, Amsterdã, junho de 2012.

${ }^{4}$ Ensaios assistidos durante a retomada de La Flûte Enchantée no Théâtre des ChampsElysées, em dezembro de 2011.

${ }^{5}$ Ensaios assistidos durante a retomada de Le Nez no Grand Théâtre de Provence (Festival de Aix), em junho e julho de 2011.

${ }^{6}$ Um dia de ensaio para a retomada de Refuse The Hour (traduzido La Négation du Temps em Francês) no Opéra-théâtre, durante o Festival de Avignon, em julho de 2012.

${ }^{7}$ Documenta é uma grande mostra de obras de artistas plásticos e de performers contemporâneas que acontece em Cassel (na Alemanha), sob a forma de uma exposição internacional que ocupa toda a cidade. Criada em 1955, ela ocorre uma vez a cada cinco anos com duraçáo de cem dias, entre junho e setembro. No verão de 2012 ocorreu a décima terceira edição, sob a responsabilidade da comissária da exposição Carolyn Christov-Bakargiev.

${ }^{8}$ The Refusal of Time, vídeo-instalação e máquina mecânica "elefante", de William Kentridge. Edição de vídeo: Catherine Meyburgh; design da máquina: Jonas Lundquist e Sabine Theunissen; música: Philip Miller. Documenta 13, Kassel, de junho a setembro de 2012.

${ }^{9}$ Peter Galison em entrevista com David Edwards, plaquette de présentation de l'exposition "La Négation du temps - Prologue", le Laboratoire, mar. 2011.

${ }^{10}$ Peter Galison em entrevista com David Edwards, mar. 2011.

${ }^{11}$ Catherine Meyburgh (edição de vídeo), Philip Miller (compositor), Sabine Theunissen (cenografia) e Luc Dewit (direção de atores).

${ }^{12}$ La Négation du temps - Prologue (exposição), no Le Laboratoire, em Paris, de março a junho de 2011.

${ }^{13}$ A subdivisão do projeto em dois eixos de criação, ao invés de uma única instalação, aconteceu somente em julho de 2011, depois da exposiçáo no Laboratoire, durante o workshop em Aix-en-Provence.

14 "In the studio this is much easier. There are different fragments [...], all around the walls of the studio. You can see them together in a glance, you can put them, juxtapose them, in different ways".

15 "a negociation between ourself and what which is outside".

16 "Rather than read his way towards a conceptualisation of a project like The Magic Flute, 
Kentridge sets to work drawing, making prints, tearing scraps of paper, constructing mechanical figures, building mini-theatres, moving ordinary objects around a table, setting up a camera and testing projections against different backdrops".

17 "Thought may follow one particular path, but there are all the other paths not taken, and all the other paths still being thought through, or not yet thought of, that language can latch on to at different stages as it goes. Which is why I have not talked of a 'stream of consciousness' that is solitary but diffuse, rather a 'highway of consciousness' where you have a channel but many different lanes and different things moving in different lanes, overtaking, stooping, leaving the highway".

\section{Referências}

GALISON Peter. L'Empire du Temps, les Horloges d'Einstein, les Cartes de Poincaré. Tradução francesa de Bella Arman. Paris: Edições Robert Laffont, 2005.

GALISON, Peter. Entrevista com David Edwards. Folder de apresentação da exposição "La Négation du temps - Prologue", no Laboratoire, mar. 2011.

GALISON, Peter; KENTRIDGE, William; MEYBURGH, Catherine; MILLER, Philip. William Kentridge: The Refusal of Time. Paris: Edições Xavier Barral, 2012.

KENTRIDGE, William. Conferência sobre Le Nez, no Hotel Maynier d'Oppède, Aixen-Provence, 1 jul. 2011(a).

KENTRIDGE, William. Entrevista com Denise Wendel-Poray. Accepter la migration de la pensée et des images. In: FOCCROULE, Bernard (Org.). Le Nez de Dmitri Chostakovitch (programa do espetáculo), Festival de Aix en Provence, 2011(b).

KENTRIDGE, William. A Negociation between Ourself and what Which is Outside. Drawing Lesson three, Vertical thinking. Conferências Norton, Harvard, 3 abr. 2012(a), KENTRIDGE, William. Drawing Lesson Two. A brief history of colonial revolts. Conferências Norton, Harvard, 27 mar. 2012(b).

KENTRIDGE, William. Encontro com o Público sobre Refuse The Hour, na Ecole d'art, Avignon, 9 jul. 2012(c).

KENTRIDGE, William. Conversation avec le Public Autour du Spectacle Refuse The Hour. Festival d'Avignon. Avignon: École d'art d'Avignon, 9 jul. 2012(d).

KENTRIDGE, William. Interview. In: LAW-VILJOEN, Bronwyn (Org.). William Kentridge Flute. Parkwood: David Krut Publishing, 2007. P. 23-37.

LAW-VILJOEN, Bronwyn (Org.). William Kentridge Flute. Parkwood: David Krut Publishing, 2007.

NAPHEGYI, Caroline Naphegyi. Expérience 12: La Négation du temps - prologue, de William Kentridge. Reportagem de Anne-Sophie Vergne, publicada em 13 abr. 2011. Disponível em: <www.youtube.com/watch?NR=1\& feature=endscreen\&v=FSAUchwbg BK>. Acesso em: 20 maio 2012. 
NAPHEGYI, Caroline. Expérience 12: La Négation du temps - Prologue de William Kentridge. Reportagem de Anne-Sophie Vergne. Disponível em: <http://www.youtube. com/watch?v=FSAUchwbgBk\&feature=youtu.be>. Acesso em: 13 abr. 2011.

THEUNISSEN, Sabine. Conversation avec l'Auteur pendant les Répétitions du Nez. Aix-en-Provence, Grand Théâtre de Provence, jul. 2011.

Fanny Le Borgne é formada em Design de espaço e Estudos Teatrais na Université Paris 3 Sorbonne-nouvelle, em 2010. É Mestre em Estudos Teatrais pela mesma universidade. Atualmente trabalha na França como cenógrafa.

E-mail: fannylb88@aol.fr

Traduzido do original em francês por André Mubarack. Revisado por Gilberto Icle.

Recebido em 01 de fevereiro de 2013

Aprovado em 10 de abril de 2013 